\title{
Psicanálise e Teoria Social à Luz da Teoria Crítica de Theodor W. Adorno
}

Psichoanalisis and Social Theory According to the Critical Theory of Theodor W. Adorno

Psicoanálisis y Teoría Social a La Luz de la Teoría Crítica de Theodor W. Adorno
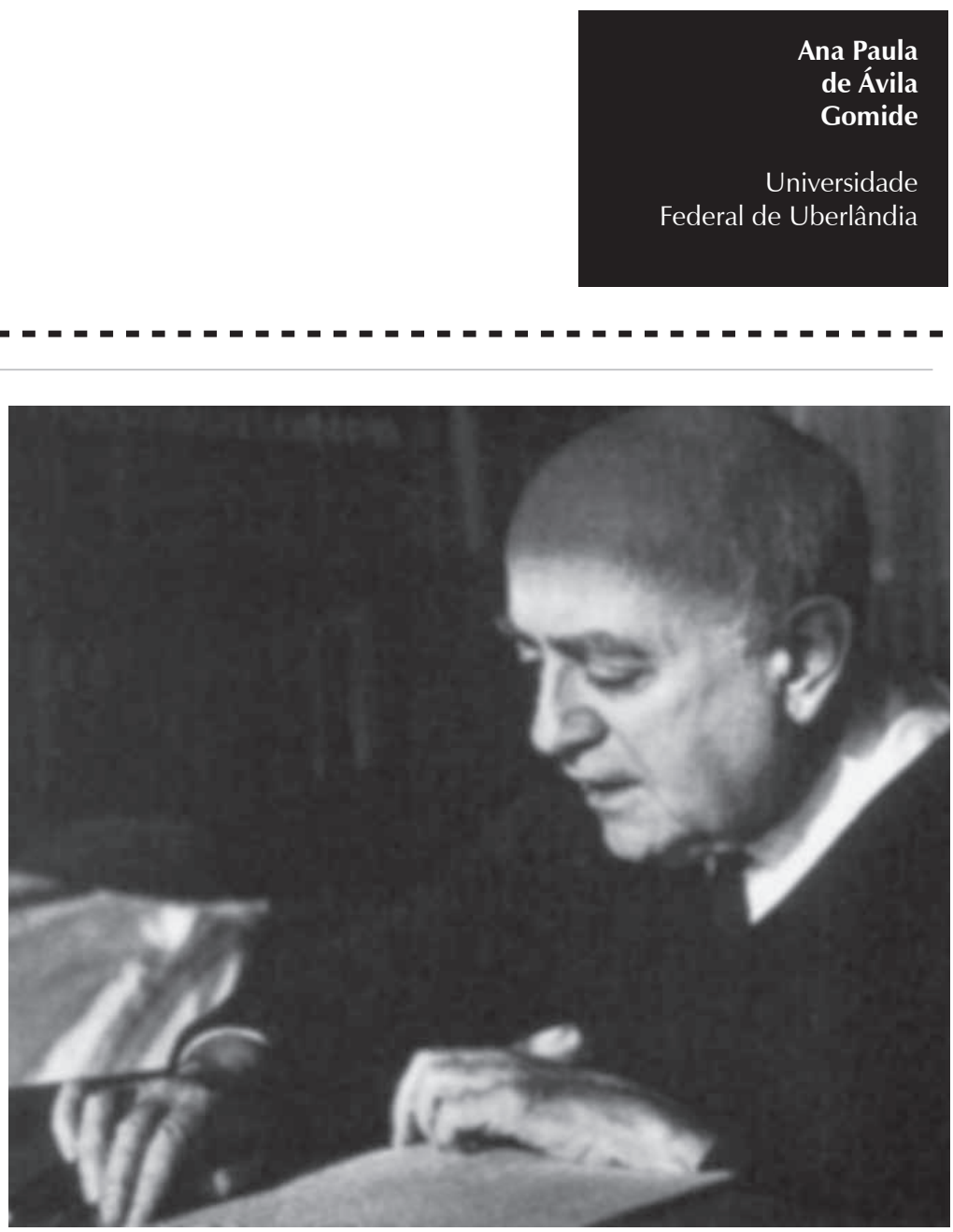
Resumo: Este trabalho propõe discutir as apropriações feitas por Adorno das categorias freudianas para sua crítica social, assim introduzindo novas questões acerca da psicanálise e de suas relações com a teoria da sociedade, sem recair nos riscos da psicologização dos determinantes sociais e da sociologização dos determinantes psíquicos. Tratamos de discutir as limitações apontadas pelo autor sobre os conceitos freudianos quando os mesmos são confrontados com as tendências históricas do capitalismo tardio. Enfim, as reflexões sobre o anacronismo da psicanálise evidenciam o quanto o objeto estudado por Freud - o indivíduo - se modificou mediante as forças econômicas e sociais expropriadoras da psicologia individual, e apontam o potencial crítico presente na psicanálise clássica por elucidar os efeitos subjetivos de formas de socialização impostas pelo modo de funcionamento das sociedades tecnicamente administradas.

Palavras-chave: Psicanálise. Teoria crítica. Formação. Indivíduo.

\begin{abstract}
This paper aims at the discussion of the appropriations made by Adorno of the Freudian categories in order to introduce new questions about psychoanalysis and its relations with the theory of society, without the risks of "psychologizing" the social determinants or "sociologizing" the psychological determinants. We try to discuss the limitations mentioned by Adorno on Freudian concepts, especially when they are confronted with the historical trends of late capitalism. The reflections on the "anachronism" of psychoanalysis show how the object studied by Freud - the individual - has changed through the economic and social forces that expropriated the individual psychology, and point to the critical potential of the classical psychoanalysis to elucidate the subjective effects of the forms of socialization imposed by the operating mode of the technically administered societies.
\end{abstract}

Keywords: Psychoanalysis. Critical theory. Formation. Individual.

Resumen: Este trabajo propone discutir las apropiaciones efectuadas por Adorno de las categorías freudianas para su crítica social, así introduciendo nuevas cuestiones acerca del psicoanálisis y de sus relaciones con la teoría de la sociedad, sin recaer en los riesgos de la psicologización de los determinantes sociales y de la sociologización de los determinantes psíquicos. Tratamos de discutir las limitaciones apuntadas por el autor sobre los conceptos freudianos cuando los mismos son confrontados con las tendencias históricas del capitalismo tardío. En fin, las reflexiones sobre el anacronismo del psicoanálisis evidencian cuánto el objeto estudiado por Freud - el individuo - se modificó mediante las fuerzas económicas y sociales expropiadoras de la psicología individual, y apuntan el potencial crítico presente en el psicoanálisis clásico por elucidar los efectos subjetivos de formas de socialización impuestas por el modo de funcionamiento de las sociedades técnicamente administradas.

Palabras clave: Psicoanálisis. Teoría crítica. Formación. Individuo.

O recurso à psicanálise freudiana para constituir um campo de reflexão sobre a modernidade e suas formas de organização social, tendo em vista o estatuto do indivíduo, sua adesão a diferentes formas de ideologias políticas, bem como sua participação nos fenômenos de massa do século XX, foi uma constante por parte de uma corrente de pensadores europeus. O pensamento freudiano também foi reconhecido por elucidar, além da clínica dos sofrimentos psíquicos, as complexas relações entre o público e o privado em termos das bases psicológicas necessárias para o funcionamento de produções culturais e para a integração dos sujeitos a vínculos sociopolíticos de diferentes naturezas. Não obstante, tais tentativas de articulação da psicanálise com a teoria social também se tornaram objeto de discussão, tendo em vista as leituras reducionistas e apressadas, encontradas em boa parte da literatura voltada para o assunto, das relações entre indivíduo e sociedade para dar conta de fenômenos sociais e de suas influências sobre a dinâmica psíquica e a formação da subjetividade.

Dentre os aspectos mais questionáveis, encontram-se os de cunho conceitual e metodológico que tentam nivelar os elementos psíquicos aos elementos sociais, assim acabando por apresentar uma leitura superficial sobre o psiquismo e a totalidade social. Citamos, por exemplo, a síntese almejada entre marxismo e psicanálise pelos representantes da chamada vertente freudomarxista, que acabou por pressupor uma leitura da sociedade livre de antagonismos 
segundo Adorno

(1955/1991), os homens não conseguem se reconhecer na sociedade e tampouco se realizar nela, porque se encontram alienados em frente ao todo e entre eles mesmos, tendo em vista as pressões socioeconômicas que os determinam e que acabam, assim, por reproduzir a situação social atual denominada sociedades individualistas ou narcísicas.
(Jacoby, 1975), no sentido de que a unificação proposta entre a Psicologia e a Sociologia tenha eliminado as tensões e os conflitos entre as duas ciências, o que constituiu uma falsa reconciliação dentro de uma visão acrítica da sociedade. O encargo de promover a unificação de Freud com o marxismo nas pesquisas interdisciplinares iniciais almejadas pelo Instituto de Pesquisa Social foi tarefa de Erich Fromm, que teve muita influência, na década de 30 , sobre a teoria crítica no exame de problemas psicossociológicos, tais como a elucidação das relações entre as transformações econômicas e o desenvolvimento do aparelho psíquico, por isso a proposta de Fromm para a integração da psicanálise aos estudos do materialismo histórico. Não obstante, o revisionismo de Fromm sobre a psicanálise acabou se tornando alvo de polêmicas e de críticas por parte de Marcuse e de Adorno (Jacoby, 1975), sendo sua influência na teoria crítica posteriormente reduzida mediante alguns acontecimentos que o fizeram perder sua legitimidade dentro da produção teórica da Escola de Frankfurt, tais como suas tentativas de revisar Freud às expensas de esvaziar o conteúdo crítico encontrado na teoria das pulsões e a modificação filosófica da teoria crítica com a entrada de Adorno, que introduziu novas questões acerca da psicanálise e de suas relações com a teoria da sociedade (Gomide, 2007).

$\mathrm{Na}$ realidade, indivíduo e sociedade encontram-se cindidos frente a uma sociedade que obtém sua unidade e integração do fato de não ser unitária ou igualitária, como afirmou Adorno (1955/1991) na análise que fez das relações da Sociologia com a Psicologia. Por sua vez, seguindo o raciocínio do autor, devemos considerar que a separação entre sociedade e psique é falsa consciência quando eterniza, por meio de categorias, a cisão historicamente estabelecida entre o sujeito vivente e a objetividade que governa os homens, mas que provém, sobretudo, deles mesmos. No entanto, segundo Adorno (1955/1991), os homens não conseguem se reconhecer na sociedade e tampouco se realizar nela, porque se encontram alienados em frente ao todo e entre eles mesmos, tendo em vista as pressões socioeconômicas que os determinam e que acabam, assim, por reproduzir a situação social atual denominada sociedades individualistas ou narcísicas. Os espaços subjetivos ou a esfera privada que apontam os estratos psíquicos têm sido colocados a serviço das demais instâncias externas de controle, perdendo, dessa forma, seu caráter particular. Ao lado das intervenções empresariais e dos grandes trustes na vida privada, encontramos as intervenções estatais e as formas de socialização coletivas em áreas como infância, saúde e educação, assim contradizendo o mito da liberdade individual e da independência da família, suscitando nos sujeitos a falsa ideia de pertencimento grupal, lado a lado com a abdicação do desejo de se estabelecer laços sociais e afetivos com outros indivíduos, reconhecidos, nesse contexto, como possíveis rivais na competição pela autoconservação e pela sobrevivência social. Mediante tal quadro político e social de coletivização técnico-administrativa e de uniformização das chamadas sociedades democráticas de massa da fase monopolista do capitalismo tardio, citamos as seguintes conclusões de Marcuse:

Essa coletivização técnico-administrativa aparece como expressão da razão objetiva (...). Todas as liberdades são predeterminadas e preconfiguradas desta forma - subordinadas não tanto ao poder político quanto às exigências racionais do aparelho. Este engloba a existência pública e privada dos indivíduos, tanto dos que dispõem como daqueles de que se dispõe, engloba o tempo do trabalho e de ócio, o serviço e o descanso, a natureza e a cultura (1974, p.54) 
A teoria crítica da sociedade, na sua apropriação de conceitos freudianos para a crítica da cultura contemporânea e da sociedade - sobretudo os autores Adorno, Horkheimer e Marcuse -, e para a compreensão histórica do indivíduo em suas conflitantes relações com a cultura que o constitui, introduziu novas questões acerca da psicanálise e de suas relações com a teoria social, sem recair nos riscos da psicologização dos determinantes sociais e da sociologização dos determinantes psíquicos. Pois bem, é nesse terreno complexo e cheio de contradições que se encontram as leituras específicas que Adorno faz da psicanálise para a sua crítica social. Visando ao entendimento de fenômenos sociais que levam à desumanização dos sujeitos (tais como o fascismo ou as diferentes formas de totalitarismos encontrados, inclusive, na sociedade democrática de massas), a análise da teoria social deve levar em conta a configuração dos indivíduos inseridos e participantes desses fenômenos. A defesa que Adorno faz da psicanálise e de sua relação com a teoria crítica se baseia no conceito de que o particular individual descrito por Freud seria uma via de entendimento e de esclarecimento dos determinantes sociais que o atravessam, pois a irracionalidade do sistema manifesta-se na psicologia do sujeito cativo sem que o mesmo tenha total consciência disso.

Assim, sobre a discussão acima apresentada, as divergências entre indivíduo e sociedade não são somente quantitativas, já que tais diferenças são resultantes de algo mais grave, a exemplo do processo social violento e desumano que imprime suas marcas nos sujeitos transformando os últimos em meros portadores da função social e obrigando-os a sacrificar suas próprias individualidades e desejos genuínos em benefício da maquinaria (Adorno, 1955/1991, p.43). Dessa forma, o indivíduo é uma mônada, mas no sentido de trazer em si a essência do coletivo de uma falsa sociedade. A psicologia que se volte adequadamente para o inconsciente tem mais possibilidades de localizar a fatalidade social do que uma que vise a se harmonizar com as categorias utilizadas pela Sociologia. Segundo Adorno (1955/1991), nas categorias da psicanálise encontra-se a realidade do todo que constitui e forma o singular, pois "uma psicologia que nada quer saber da sociedade e se empenha, à sua maneira, em não sair do indivíduo e de sua herança arcaica expressa mais sobre a fatalidade social que a que se articula com uma universitas literarum aqui inexistente" (p. 39). Diferentemente dos revisionistas e dos neofreudianos, Adorno dirige sua crítica e suas análises dos conceitos freudianos buscando determinar, dentro dos próprios conceitos, seus conteúdos de verdade assim como seus falsos elementos, ressaltando os desdobramentos históricos que o objeto da psicanálise vem sofrendo. Os núcleos materialistas que são imanentes às categorias psicanalíticas são extraídos tendo em vista os momentos históricos que têm minado a categoria de indivíduo, considerando-se que a psicanálise, ao mostrar o caráter conflituoso do sujeito, apresenta e elucida a negatividade da própria psicologia individual, qual seja, a impossibilidade de um indivíduo autônomo e livre em uma cultura e sociedade não livres. As apropriações adornianas da psicanálise servem para apontar os motivos subjetivos do consentimento dos homens relativo às forças sociais irracionais e desumanas que, não obstante, vão contra os interesses racionais dos indivíduos. Freud, segundo Adorno (1946/1971), em sua persistência sobre a "atomística existência do indivíduo", acabou por penetrar, de forma paradoxal, no segredo histórico da dominação do homem quando alcançou o social presente na Psicologia - por exemplo, quando Freud constatou a proibição do incesto e a interiorização do superego, 
entre outros, que dão base à formação do caráter, esse resultante de condicionantes sociais.

Levando em conta a diversidade de linhas de reflexão em que bases teóricas diversas têm composto o pensamento adorniano, o intuito deste trabalho é investigar, a partir de alguns textos de Adorno voltados para questões e fenômenos sociais, de que forma a psicanálise freudiana e, mais propriamente, alguns conceitos psicanalíticos se inserem no pensamento desse autor. As categorias psicanalíticas foram utilizadas nas discussões de Adorno sobre o fascismo, sobre os fenômenos concernentes aos movimentos de massa contemporâneos que fazem parte das sociedades tecnicamente administradas, sobre o antissemitismo e sobre a formação de "personalidades preconceituosas".

Para os propósitos deste trabalho, trataremos de discutir, especificamente, algumas críticas de Adorno dirigidas a Freud que podem ser encontradas nos seguintes trabalhos: Sobre música popular (1941/1986) - escrito com Simpson -, Elementos do anti-semitismo: limites do esclarecimento" - texto escrito com Horkheimer e que se encontra na obra Dialética do Esclarecimento (1944/1985) -, e o texto De la Relación entre Sociología y Psicología (1955/1991). A nosso ver, as apreciações rigorosas de Adorno feitas sobre a psicanálise devem-se ao intuito do autor de querer delimitar, ainda de forma mais contundente, o potencial crítico das categorias freudianas quando, ao serem confrontadas com as aflições psicológicas contemporâneas que se tornaram convenientes para o funcionamento social do mundo administrado, são empregadas para elucidar os efeitos subjetivos de formas de socialização impostas pelo modo de funcionamento do capitalismo avançado. Com isso, Adorno visa a extrair a base materialista do pensamento psicanalítico, considerando as sociedades modernas do século XX e os rumos tomados por elas em direção à consolidação dos regimes e sistemas totalitários que, por sua vez, acabaram por solapar a categoria de indivíduo em benefício do poder e do desenvolvimento de forças econômicas. Nessa direção, ao refletir sobre as limitações da psicanálise em contraposição às transformações históricas do capitalismo, Adorno tem como objetivo evidenciar o quanto o objeto estudado por Freud - o indivíduo - se modificou ao entrar em contato com as forças econômicas e sociais do capitalismo avançado.

\section{A superação histórica da psicanálise no mundo administrado: o anacronismo e a validade da teoria freudiana}

Adorno (1955/1991), também indica e sustenta que a teoria psicanalítica consiste em um saber que preserva o indivíduo frente à objetividade cujo aparato técnico tem contribuído para a sua supressão quando essa teoria psicológica ainda pressupõe um espaço psíquico "extrassocial", na qual a "diferenciação individual" é resguardada. Assim, a Psicologia se torna uma forma de resistência, e a psicanálise, a melhor teoria psicológica, posto que seu poder de emancipação está ligado à denúncia dos fatores que impedem a diferenciação e a realização do indivíduo na cultura (Freud, 1930/1974). Isso quer dizer que os mesmos componentes encontrados na psicanálise que se tornaram objetos de crítica de Adorno também foram lembrados e ressaltados pelo mesmo como suportes teóricos importantes para expressar e esclarecer a fatalidade social que tem minado a categoria de indivíduo. Mesmo que Freud tenha oposto indivíduo e sociedade assim apontando a cisão entre tais esferas em vista dos conflitos e tensões gerados 


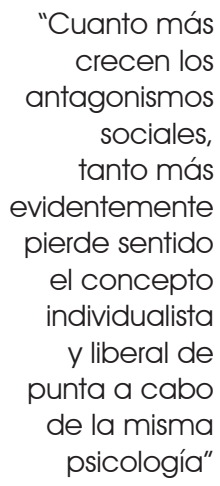

(Adorno, 1955/1991, p.75). pela cultura na constituição individual, em algumas de suas formulações (nas suas investigações sobre a psicologia de grupo, por exemplo), Freud pôde atestar os vínculos existentes entre os níveis psicológicos e sociais (Adorno, 1951/1972). Nas antinomias encontradas em Freud, podemos retirar da psicanálise um instrumento de reflexão sobre a cultura, daí a declaração de Adorno: "Freud tinha razão quando não tinha razão" (1946/1971, p. 150).

Um dos problemas a ser discutido neste trabalho refere-se à questão levantada por Adorno a respeito da superação histórica da psicanálise em face de um mundo totalmente socializado. É o que o autor revela, por exemplo, ao afirmar que, se o mundo préburguês não conhecia ainda a Psicologia, tampouco as sociedades totalitárias a reconhecem como esfera do diferenciado, de oposição à brutalidade do exterior, sendo os impulsos contrários à civilização cada vez mais apropriados pelos poderes sociais: "Cuanto más crecen los antagonismos sociales, tanto más evidentemente pierde sentido el concepto individualista y liberal de punta a cabo de la misma psicología" (Adorno, 1955/1991, p.75). Considerandose a influência da coletividade sobre a esfera particular, da qual citamos todas as formas de políticas totalitárias que vigoraram nos países europeus no século XX, e que, nas sociedades industriais, as demais instâncias de poder se tornaram racionalizadas, exaurindo, assim, qualquer forma de resistência individual frente à tendência totalizadora, o espaço psíquico, por sua vez, se empobreceu e se modificou, tomando como base a mônada psíquica estudada por Freud em termos de dinâmica psicológica dos conflitos entre inconsciente e consciente, e depois, na tríade id, ego e superego. Dessa forma, a psicanálise tornou-se obsoleta, pois seu objeto sofreu alterações: a psique dividida entre inconsciente e consciente se dissolveu face à crescente irracionalidade do todo. Todavia, Adorno vai requisitar a psicanálise em "sua figura autêntica" e já superada sem deixar de fazer críticas às categorias freudianas - para as suas reflexões sobre o nazismo e as sociedades administradas quando se volta para a configuração atual de indivíduo que, não obstante, pode revelar as formas de dominação mais sofisticadas e tecnologicamente mediadas e as tendências sociais imperantes.

No texto Sobre música popular, Adorno (1941/1986), ao fazer uma análise sobre os processos sociais envolvidos nos produtos difundidos pela indústria cultural - no caso, a música popular - que têm imposto formas de comportamento regressivas aos seus consumidores (ouvintes), constata que os sujeitos se encontram menos diferenciados devido à estandardização da cultura, ou melhor, dos produtos culturais mercantilizados (Adorno \& Simpson, 1941/1986). Quanto à estrutura social e às suas formas de "manipulação das massas", diz Adorno que os mecanismos de controle da indústria de consumo se tornaram bem poucos velados para a consciência de seus consumidores, existindo, assim, uma deliberada resolução, por parte dos sujeitos, de aceitar (forçosamente) os produtos que Ihes são impingidos. Dada a natureza da música popular, esta possui um sistema de mecanismos e de técnicas que exige de seus ouvintes reações automáticas e canalizadas pelo padrão comercial e que são totalmente antagônicos ao ideal de individualidade de uma sociedade livre, liberal. Com isso, mediante esse quadro de conformismo social favorecido pela adesão massiva das pessoas aos ditames da diversão comercial padronizada, Adorno questiona até que ponto ainda se legitima a distinção sustentada 
por Freud entre o consciente e o inconsciente. Nas palavras de Adorno:

Na atual situação, talvez seja, por essas razões - que são apenas exemplos de fenômenos muitos amplos da psicologia das massas -, apropriado perguntar até que ponto ainda se justifica toda a distinção psicanalítica entre o consciente e o inconsciente. As atuais reações das massas são bem pouco veladas da consciência (Adorno \& Simpson, 1941/1986, p.146)

Ao levantar esse problema, na realidade, a preocupação de Adorno se relaciona à seguinte situação paradoxal: a mentira manifesta dos ideais coletivos, bem como a irracionalidade dos estímulos produzidos pela indústria cultural, são reconhecidas pelas pessoas que a eles aderem; entretanto, por que as pessoas se adaptam a esses ideais? A resposta estaria na psicologia dos sujeitos (da cegueira radicada nas suas próprias psicologias) que, pressionados por todos os lados pelos agentes coletivos, encontrariam nesses produtos formas de satisfação precárias, posto não haver outro modo de sustentar a autoconservação e obter o prazer (mesmo que fajuto), senão por meio do ajustamento social. O que ocorre é a transferência de energia libidinal para a aceitação ressentida do consumidor aos materiais de consumo impostos, sendo que tal aceitação (a decisão de se conformar) se daria próxima à superfície da consciência, e não completamente de forma inconsciente. Dentro desse esquema, sendo a espontaneidade individual suprimida e o ego obrigado a se conformar e a aceitar o logro das propagandas publicitárias, a linha tênue de divisão entre o inconsciente e o consciente acaba se dissolvendo, o que significa tanto a expropriação dos desejos individuais pelo aparato social do consumo como a obrigação de o sujeito ter de, conscientemente, sacrificar seu poder de julgamento racional sobre a mentira propagada. $\mathrm{O}$ indivíduo teria que distorcer sua própria percepção da realidade para tentar, forçosamente, ajustar seus interesses ao que a realidade lhe oferece, sendo que o ajustamento às agências sociais objetivas tende a fornecer aos sujeitos a ideia de que fazem parte de uma coletividade. Assim:

O paradoxo da situação é que é quase insuperavelmente difícil romper esse fino véu. Mesmo assim, a verdade não é mais subjetivamente tão inconsciente quanto se esperava que fosse. Isso se mostra pelo fato de que, na práxis política dos regimes autoritários, a mentira ostensiva, na qual ninguém efetivamente acredita, está cada vez mais substituindo as 'ideologias' de ontem, que tinham o poder de convencer aqueles que acreditavam nelas (...). Pelo contrário, a espontaneidade é consumida pelo tremendo esforço que cada indivíduo tem de fazer para aceitar o que lhe é imposto - um esforço que se desenvolveu exatamente porque o véu que recobre os mecanismos de controle se tornou tão tênue (Adorno \& Simpson, 1941/1986, p. 146)

A discussão que Adorno levanta acerca da pequena possibilidade de diferenciação (de individuação) do indivíduo nas sociedades administradas, em termos da dinâmica psíquica estudada por Freud, vincula-se às transformações sociais que pouco têm necessitado dos agentes mediadores da personalidade (o ego) para a adaptação social e que Freud postulara nas suas descobertas sobre o aparelho psíquico, o que, por sua vez, confirma a superação histórica do indivíduo das sociedades liberais e, assim, a obsolescência da psicanálise, já que ela constitui uma teoria baseada nas formas de subjetivação da fase da concorrência econômica. Nessa mesma direção é que Adorno vai afirmar, em outro texto, que "el mandato freudiano 'donde era ello, debe llegar a ser yo' contiene algo de estoicismo vacío, de inevidente" (Adorno, 1955/1991, p.159). O indivíduo, assim, não possui outros meios para escapar das recorrentes exigências e provas de um sistema regido por um ordenamento mercantil e hierárquico, e as decisões individuais são 
fornecidas, de antemão, por essas mesmas hierarquias, configurando a falsa ideia de harmonia entre indivíduo e sociedade. Essa falsa harmonia revela-se nociva: significa que satisfazer as necessidades individuais (que são externas aos sujeitos) consiste em seguir as regras do jogo da publicidade, condenando, assim, à irracionalidade a própria racionalidade da autoconservação e, por isso, as funções egóicas se enfraquecem (Adorno, 1955/1991, p.158). Essa falsa unidade entre indivíduo e sociedade significa que a tendência geral da sociedade irrompe nos homens e impede, assim, a individuação. Sobre isso, acrescenta o autor: "La naciente identidad no es reconciliación de lo general y lo particular, sino lo general como absoluto donde desaparece lo particular" (Adorno, 1955/1991, p.81), e é claro, o particular a que Adorno se refere é o indivíduo estudado pela psicanálise freudiana. Na ordem existente, as funções cognitivas do ego - o órgão da consciência - são reprimidas para que as pulsões individuais, que dão sustentação ao mercado, possam ser mais ou menos liberadas e conformadas aos objetos de consumo. E, ainda, na sociedade predominantemente administrada, as decisões que os sujeitos têm que tomar são relativas a escolher o mal menor (na esfera do trabalho, nos produtos de consumo massificados e na escolha política de candidatos), sendo que, também para a esfera inconsciente, poucas são as possibilidades de escolha. Para o sujeito sobreviver nessa cultura, é preciso regredir, e, de certa forma, aceitar o véu social que oculta a injustiça generalizada, daí verificarse o que Adorno tem apontado como a "transposição do ego ao inconsciente", posto que, na produção social vigente, também as possibilidades de sublimação da energia libidinal se tornaram mínimas, sendo a mesma racionalmente administrada. Nas palavras de Adorno:

También las posibilidades de elección son tan reducidas para el inconsciente, si es que no son escasas ya en origen, que los grupos con intereses que marcan la pauta las desvían por muy pocos canales con métodos comprobados hace mucho por la técnica psicológica en los estados totalitarios y no totalitarios. El inconsciente (...). En su pobreza e indiferenciación se encuentra feliz y oportunamente con la homogeneización de un mundo administrado (1955/1991, p.162).

O inconsciente, harmonizando-se com o todo social, e a consciência, retrocedendo ao inconsciente, faz com que, nesse "contínuo entre sociedade e indivíduo" (ou seja, no prolongamento da racionalidade econômica dentro da esfera psíquica) provocado pelo assédio constante da indústria cultural e de leis econômicas sobre os modos de vida dos sujeitos, o enfrentamento das forças psíquicas estudadas por Freud sejam expropriadas pelo todo homogeneizante. Não obstante, no texto Sociologia e Psicologia, Adorno chega a afirmar que "el psicoanálisis, em su forma auténtica e históricamente superada, adquiere su verdad como relato sobre los poderes de la destrucción que cunden en lo particular en medio de lo destructivo general" (Adorno, 1955/1991, p.74). A nosso ver, Adorno utiliza as categorias psicanalíticas, ou melhor, a psicanálise autêntica, para refletir sobre as formas de dominação referentes à subjetividade, pois as categorias psicanalíticas tornam-se indispensáveis para revelar o lado subjetivo da irracionalidade objetiva, e sobre os mecanismos psicológicos requeridos por tais tendências dominantes que têm se utilizado da energia pulsional dos sujeitos para forçar a integração à sociedade. Dessa perspectiva, um dos temas centrais de Adorno para a explicação do nazi-fascismo é tentar delimitar quais os elementos determinantes da fragilidade do indivíduo e da debilidade do ego, no sentido de que, com o enfraquecimento da instância psíquica encarregada de estabelecer relação com a realidade externa, as pessoas recaem 
na heteronomia. Entretanto, os processos de integração das sociedades administradas têm debilitado o ego dos sujeitos. No texto Sociologia e Psicologia, Adorno, ao se referir à categoria ego formulada por Freud, afirma que:

Allí donde el yo no alcanza su propria peculiaridad, su diferenciación, há de efectuar alguna regresión, sobre todo a lo que Freud Ilamó libido del yo, con la que está estrechamente emparetado, o al menos mezclar sus funciones conscientes com otras inconscientes. Lo que em realidad aspiraba a ir más allá del inconsciente vuelve a entrar una vez más a su servicio $y$, de esse modo, a fortalecer en lo posible sus impulsos (Adorno,1955/1991, p.183)

A partir da citação acima, as referências de Adorno ao ego, na análise desse conceito à luz das tendências sociais imperantes, visa, na verdade, a esclarecer as novas formas de subjetivação correspondentes às transformações socioeconômicas do capitalismo tardio de uma cultura marcada pela padronização e pela pressão totalitária dos movimentos de massa. Assim, seguindo o raciocínio do autor, as agências de publicidade e seus mecanismos de controle, mobilizando e apropriando-se desses comportamentos regressivos, convertem os comportamentos narcisistas em modelos de comportamento, em formas de adaptação social condizentes com a irracionalidade objetiva. O poder social não mais tem necessidade de um ego forte, mediador, como era requerido na época liberal do capitalismo, porque, no século XIX, a racionalidade predominava, diferentemente de hoje, época da sociedade administrada (Horkheimer \& Adorno, 1944/1985). Isso se relaciona, precisamente, à questão apontada por Adorno de que os conflitos psicológicos, hoje, se dão mais na área do narcisismo, que se refere a uma forma de adaptação atual na qual o sujeito utiliza a ordem para satisfazer seus desejos e para preservar seus impulsos de autoconservação (as denominadas sociedades individualistas ou narcísicas), enquanto as neuroses clássicas, estudadas por Freud no século XIX, retrocedem. É o que entendemos das citações abaixo:

En el narcisismo, al menos en aparencia, se salvaguarda la función de autoconservación del yo, pero al mismo tiempo se escinde de la función de conciencia y queda abandonada en manos de la irracionalidad. Todos los mecanismos de defensa tienen un sello de narcisismo: el yo experimenta lo mismo su debilidad frente a la pulsión que su impotencia real como 'herida narcisista' (Adorno, 1955/1991, p.184)

\section{E acrescenta:}

En realidad, se movilizan selectivamente aquellos mecanismos de defensa infantiles que, según la situación histórica, mejor se adapten al esquema de los conflictos sociales del yo. Sólo esto, y no el tan citado cumplimiento de deseos, llega a explicar la autoridad de la cultura de masas sobre los hombres (Adorno, 1955/1991, p.187)

As formas narcisistas predominantes, com o simultâneo enfraquecimento das funções do ego, indicam o triunfo da sociedade sobre o indivíduo, pois os conflitos são dissolvidos na cultura que, ilusoriamente, com seus mecanismos de controle, visa a atender as necessidades mais regredidas dos sujeitos, fortalecendo suas tendências narcisistas mais primitivas. Os vínculos que os sujeitos desenvolvem com as forças sociais são de teor irracional, dado que as leis do inconsciente foram apropriadas pelas leis do consumo e pelas demais formas institucionalizadas de poder.

As questões suscitadas por Adorno acerca da superação histórica da psicanálise no mundo altamente socializado também aparecem no texto Elementos do anti-semitismo, especificamente, no elemento VII, ao ilustrar as "novas configurações de indivíduos" que, de acordo com os frankfurtianos, constituem os traços de caráter concernentes às formas de 
ajustamento social requerido em cada época histórica que, no capitalismo avançado, Adorno denomina "mentalidade do ticket". Nesse texto, Adorno delineia uma pré-história do antissemitismo e de suas manifestações subjetivas e objetivas ao longo da História até a emergência do nacional-socialismo na Alemanha, e, com isso, no período do capitalismo monopolista, ao constatar as transformações do progresso técnico, conclui que a racionalidade econômica cada vez mais operante determinou, por sua vez, transformações nas estruturas psíquicas dos indivíduos que também provocaram "novas formas de antissemitismo". Se, na época liberal, "o anti-semitismo ainda era um tema aberto à escolha subjetiva", na era dos monopólios, a psicologia antissemita foi substituída pelos estereótipos oferecidos pelos tickets fascistas ou pelo "inventário de slogans da grande indústria militante" (Horkheimer \& Adorno, 1944/ 1985, p.187).

Dessa tendência objetiva em que a racionalidade econômica consegue remodelar não só as organizações comerciais e os ramos do negócio como também os próprios homens, pode-se perceber a padronização psicológica, o que significa que, em termos subjetivos, os sujeitos acabam aderindo de forma imediata (e não mais por meio de ponderações) aos elementos oferecidos pela realidade social circundante, tais como às facções políticas padronizadas ou aos ideais coletivos suscitados pela indústria cultural. Assim, dentro dessa heteronomia generalizada, no que se refere à dinâmica psíquica, Adorno chega à conclusão que a mônada psíquica freudiana se tornou retrógrada. É o que Adorno indica na passagem abaixo:

A psicanálise apresentou a pequena empresa interior que assim constituiu uma dinâmica complicada do inconsciente e do consciente, do id, ego e superego. No conflito com o superego, a instância do controle social no indivíduo, o ego mantém as pulsões dentro dos limites da autoconservação (...). Mas, na era das grandes corporações e das guerras mundiais, a mediação do processo social através das inúmeras mônadas mostra-se retrógrada. Os sujeitos da economia pulsional são expropriados psicologicamente e essa economia é gerida racionalmente pela própria sociedade. A decisão que o indivíduo deve tomar em cada situação não precisa mais resultar de uma dolorosa dialética interna da consciência moral, da autoconservação e das pulsões (Horkheimer \& Adorno, 1944/1985, p.189).

No trecho acima, o indivíduo descrito pela psicanálise freudiana correspondia, de fato, à época do liberalismo econômico, mas hoje, em termos psicanalíticos, de qual indivíduo podemos falar? Tendo em vista a pressão social que se apresenta cada vez mais racionalmente sofisticada sobre o indivíduo do capitalismo avançado, entendemos que se apresenta de forma mais arcaica ou empobrecida. Ora, os remanescentes irracionais - aqueles mesmos apontados na doutrina freudiana sobre os conflitos inconscientes - relativos à psicologia liberal tornaram-se hoje lubrificantes ou dispositivos para a produtividade social. O cerne do problema é a expropriação da psicologia privada pela hierarquia social, que significa não só a exploração dos núcleos inconscientes dos indivíduos pelos esquemas da indústria cultural, em que os impulsos internos dos consumidores são ilusoriamente satisfeitos e descarregados, como também a transformação do que restou de julgamento moral e racional dos sujeitos, algo inócuo mediante os imperativos fornecidos pelas agências sociais. Nesse sentido, as observações que Adorno faz sobre algumas características atribuídas ao indivíduo na época liberal do capitalismo destacam que, embora o sujeito no século XIX fosse submetido ao jugo de uma formação autoritária e coibitiva proveniente de relações estabelecidas dentro de instâncias familiares e religiosas, sua constituição psicológica, todavia, ainda que conflituosa, 
Freud

(1930/1974), em seus estudos dos conflitos psíquicos, já previra a decadência do liberalismo na esfera privada e na família burguesa, assim revelando a

decadência e o empobrecimento do indivíduo. possibilitava sua relativa autonomia como sujeito capaz de se adaptar às novas condições econômicas e técnicas do capitalismo, ou como assalariado ou como empresário - o tipo ideal do homo oeconomicus salvaguardando sua capacidade de resistir e de entrar em conflito com a sociedade reprodutiva que pudesse anular seus interesses individuais mais privativos (Horkheimer \& Adorno, 1944/1985). Já em relação à época contemporânea do capitalismo dos monopólios, o autor argumenta que a autonomia individual desapareceu com o concomitante empobrecimento psíquico dos sujeitos face à irracionalidade objetiva.

Das observações acima, então, pressupomos que as críticas de Adorno a Freud, no sentido de questionar a aplicação psicanalítica às novas formas de sujeitos submetidos à racionalidade econômica da sociedade industrial, se devem ao intuito do autor de ressaltar o declínio da razão individual em face do poder do todo irracional que condena o homem, a sua psicologia, ao anacronismo: "O progresso da sociedade industrial, que devia ter eliminado como que por encanto a lei da pauperização que ela própria produzira, acaba por destruir a idéia pela qual o todo se justificava: o homem como pessoa, como portador da razão" (Horkheimer \& Adorno, 1944/1985, p.190). E as críticas de Adorno servem tanto para apontar a falsidade da invariância atribuída ao indivíduo pela Psicologia no contexto de uma sociedade liberal (que nega o caráter social e histórico do indivíduo em sua forma burguesa) como também, e principalmente, para atestar que o desenvolvimento econômico tem contribuído para eliminar os últimos traços da psicologia individual (esfera psíquica socialmente mediada) que salvaguardavam alguma resistência à totalidade. Nesse sentido, a respeito das limitações apontadas por Adorno (1955/1991) sobre o modelo freudiano da empresa interior (da dinâmica do inconsciente e consciente) podemos dizer que trazem em seu bojo uma discussão sobre os mecanismos de controle que têm capturado os "traços radicalmente individuais" dos sujeitos em nome da sociedade totalizadora, o que possibilita confrontar a formação individual liberal (que ainda pressupunha alguma resistência à realidade, mesmo que em forma de produção de neurose) com a formação individual atual. Tais discussões também se encontram na pesquisa The authoritarian personality (Adorno, FrenkelBrunswick, Levinson, \& Sanford, 1950), cujos resultados empíricos, discutidos por Adorno sobre o tipo psicológico de escore baixo da Escala F, denominado liberal genuíno (sujeitos menos propensos ao preconceito), apontam a discussão com respeito aos contrapontos entre a formação liberal, que pressupunha alguma forma de racionalidade do indivíduo, e a formação atual, na qual as regressões psíquicas e a debilidade do ego são preponderantes. A verdade da psicanálise frente ao quadro atual - de que a dominação social devolve os sujeitos a um estado arcaico de configuração psíquica -, seria, contraditoriamente, extraída de seus limites e insuficiências. Freud (1930/1974), em seus estudos dos conflitos psíquicos, já previra a decadência do liberalismo na esfera privada e na família burguesa, assim revelando a decadência e o empobrecimento do indivíduo.

Segundo Adorno (1951/1972), Freud pôde adiantar, por meio de seu discernimento teórico sobre a dinâmica psicológica do indivíduo do final do século XIX, algumas características psíquicas ou "aflições psicológicas" que hoje, na época do capitalismo dos monopólios, se fazem predominantes nos sujeitos que se encontram cada vez mais psicologicamente empobrecidos por forças sociais dominantes que os atravessam. Tal discussão se encontra no texto Freudian theory and the pattern of fascist propaganda, no qual Adorno faz 
menção à obra de Freud Psicologia de Grupo e a Análise do Ego: "According to Freud the problem of mass psychology is closely related to the new type of psychological affliction so characteristic of the era which for socio-economic reasons witnesses the decline of the individual and his subsequent weakness" (Adorno, 1951/1972, p.411). O empobrecimento dos indivíduos não significa que os mecanismos psíquicos tenham sido exterminados; ao contrário, significa que os mesmos foram retirados dos sujeitos pelos poderes sociais, contribuindo para maior eficiência do sistema. Assim, a irracionalidade faz parte do funcionamento social, e não mais somente corresponde às profundezas psíquicas do inconsciente individual. Na medida em que a mônada freudiana (id, ego e superego, o jogo de forças entre tais instâncias) pressupõe o papel do ego (responsável pelo teste da realidade), instância capaz de opor resistência à irracionalidade objetiva e às forças inconscientes, torna-se de suma importância reavaliar a importância do iluminismo freudiano contido na sentença "que o id se torne ego", indicada por Adorno em outros momentos. Nesse sentido, encontra-se subjacente às reflexões e às apropriações de Adorno das categorias psicanalíticas a proposta da pesquisa $A$ personalidade autoritária (1950), que é a de possibilitar a substituição das formas de manipulação do irracional pelo trabalho da autorreflexão rumo à autonomia do indivíduo e, por isso, a importância do estudo da interioridade do indivíduo mediante o estudo da irracionalidade crescente que se encontra nas sociedades modernas. A crítica ao indivíduo deve ser a crítica à sociedade.

Adorno delimita a importância da psicanálise como um saber crítico: ela deve também denunciar, ao apontar os limites de seu objeto, as condições objetivas que têm impedido o desenvolvimento do indivíduo e suas possibilidades de diferenciação, por meio do estudo sobre as forças sociais destruidoras presentes na mônada e incorporadas na Psicologia - ou seja, a Psicologia se torna um instrumento importante quando estuda os mecanismos sociais que se mantêm no psiquismo, tendo em vista que o indivíduo é socialmente mediado e que a realidade não tem contribuído para a felicidade e para a liberdade potencial, mas, ao contrário, tem reforçado e providenciado os potenciais antidemocráticos dos sujeitos, assim impedindo a oposição à realidade encarnada na ideia monadológica de interesses individuais. As identificações dos sujeitos com os poderosos substitutos da autoridade, providenciados pela cultura totalitária - a raça, o líder fascista, as facções políticas autoritárias e os produtos fungíveis da indústria de consumo pelo mass media -, também exigem, para seu entendimento, o conhecimento psicanalítico, visto que a capacidade de resistência individual ao princípio de realidade opressor tem sido eliminada, gradualmente, pelos agentes sociais de formação dos sujeitos que imperaram na vida econômica do capitalismo tardio. O conformista que se sente forçado a se identificar com a realidade e que, no fundo, é o homem frustrado e secretamente hostil à civilização (Freud, 1930/1974) corresponde ao "tipo psicológico" emergente do desenvolvimento histórico da civilização burguesa voltada, exclusivamente, para a autoconservação. $O$ desenvolvimento técnico acelerado, que se dirige para maior controle da natureza, distorceu os objetivos de autoconservação e exagerou os mesmos na presente fase do esclarecimento (Horkheimer \& Adorno, 1944/1985). Assim, a estrutura social e econômica, baseada no planejamento e na racionalização de todas as esferas da vida, fez com que os componentes da sociedade empregassem todas as suas energias psíquicas para a preservação do sistema produtivo -assim colocando a 
autoconservação a serviço da maquinaria social, e não da felicidade humana -, e com que os mesmos externalizassem suas pulsões destrutivas para a realidade, posto que interesses econômicos têm minado os espaços simbólicos privados importantes para a formação e a "diferenciação psíquica" (Horkheimer \& Adorno, 1944/1985).

Adorno, conforme este trabalho tentou demonstrar, fez uso dos conceitos freudianos porque esses conceitos, em termos dos limites encontrados nos mesmos em confronto com as tendências históricas, dizem respeito ao particular (ao indivíduo) e lançam luz no universal presente na Psicologia, mesmo à revelia da própria psicanálise - os fatores sociais e históricos regressivos e/ou progressivos que se encontram presentes na nossa cultura.

Ana Paula de Ávila Gomide

Doutora em Psicologia pela USP/SP, Docente do Instituto de Psicologia da UFU, Uberlândia - MG - Brasil.

E-mail: anapaula@fapsi.ufu.br

Endereço para envio de correspondência:

R. Maria Dória Cunha, 160, Apt. 302- Bairro Jd. Finotti,, Uberlândia - MG - Brasil CEP: 38408-080

Recebido 14/9/2010, 1ạ Reformulação 15/10/2010, Aprovado 29/10/2010 
Adorno, T. W. (1991). De la relación entre sociología y psicología. Barcelona: Ediciones Paidós. (Trabalho original publicado em 1955)

Adorno, T. W. (1972). Freudian theory and the patterns of fascist propagand. Frankfurt: Suhrkamp. (Trabalho original publicado em 1951)

Adorno T. W., Frenkel-Brunswick, E., Levinson, D. J., \& Sanford, R. N. (1950). The authoritarian personality. New York: Harper \& Brother.

Adorno, T. W., \& Simpson, G. (1986). Sobre música popular. São Paulo: Ática. (Trabalho original publicado em 1941)

Adorno, T.W. (1971). La revisión del psicoanalisis. Madrid: Taurus Ediciones. (Trabalho original publicado em 1946)

Freud, S. (1974). O mal-estar na civilização. In S. Freud. Obras completas de Sigmund Freud. (J. Salomão, Trad., Vol. 21, pp.75 - 174), Rio de Janeiro: Imago. (Trabalho original publicado em 1930)
Gomide, A. P. A. (2007). Um estudo sobre os conceitos freudianos na obra de T. W. Adorno. Tese de doutorado, Instituto de Psicologia, Universidade de São Paulo, São Paulo.

Horkheimer, M., \& Adorno, T. W. (1985). Dialética do esclarecimento. Rio de Janeiro: Zahar. (Trabalho original publicado em 1944)

Horkheimer, M., \& Adorno, T. W. (1973). Temas básicos da sociologia. São Paulo: Cultrix. (Trabalho original publicado em 1956)

Jacoby, R. (1975). Amnésia social - uma crítica à psicologia conformista de Adler a Laing. Rio de Janeiro: Zahar.

Marcuse, H. (1974). Teoria das pulsões e liberdade. In H. Marcuse, Progresso social e liberdade (pp. 31-70). Porto: Ed. Textos Marginais. 